\title{
Click reaction synthesis of carbohydrate derivatives from ristocetin aglycon with antibacterial and antiviral activity
}

\author{
Gábor Pintér ${ }^{\mathrm{a}}$, Ilona Bereczki ${ }^{\mathrm{a}}$, Gyula Batta ${ }^{\mathrm{b}}$, Réka Ötvös ${ }^{\mathrm{a}}$, Ferenc Sztaricskai ${ }^{\mathrm{a}}$, Erzsébet Rőth ${ }^{\mathrm{a}}$, \\ Eszter Ostorházi ${ }^{c}$, Ferenc Rozgonyi ${ }^{c}$, Lieve Naesens ${ }^{\mathrm{d}}$, Mariann Szarvas ${ }^{\mathrm{e}}$, Zoltán Boda ${ }^{\mathrm{e}}$, Pál Herczegh ${ }^{\mathrm{a}, *}$ \\ a Department of Pharmaceutical Chemistry, University of Debrecen, Egyetem tér 1, H-4010 Debrecen, Hungary \\ ${ }^{\mathrm{b}}$ Department of Organic Chemistry, University of Debrecen, Egyetem tér 1, H-4010 Debrecen, Hungary \\ ' Microbiology Laboratory, Department of Dermatology, Venerology and Dermatooncology, Semmelweis University, Mária u. 41., H-1085 Budapest, Hungary \\ ${ }^{\mathrm{d}}$ Rega Institute for Medical Research, Katholieke Universiteit, B-3000-Leuven, Belgium \\ e IInd Department of Medicine, University of Debrecen, Nagyerdei krt. 98., H-4032 Debrecen, Hungary
}

\section{A R T I C L E I N F O}

\section{Article history:}

Received 21 February 2010

Revised 18 March 2010

Accepted 23 March 2010

Available online 27 March 2010

\section{Keywords:}

Ristocetin

Glycopeptide antibiotic

Antibacterial

Anti-influenza virus

Click reaction

\begin{abstract}
A B S T R A C T
New sugar derivatives of ristocetin were prepared by copper-catalyzed 1,3-dipolar cycloaddition reaction using azido-ristocetin aglycon and various propargyl glycosides. Some of them were found to be active against Gram-positive bacteria and showed favorable antiviral activity against the H1N1 subtype of influenza A virus.
\end{abstract}

(c) 2010 Elsevier Ltd. All rights reserved.
Ristocetin A (1) is a glycopeptide-type antibiotic produced by Nocardia lurida. ${ }^{1}$ The ristocetin molecule carries 6 sugar molecules (2 D-mannose, D-glucose, D-arabinose, L-rhamnose and L-ristosamine) linked to the aglycon. In spite of its good antibacterial activity against Gram-positive strains including MRSA, ${ }^{2}$ this antibiotic has not been used in therapy due to its ability to cause aggregation of blood platelets. ${ }^{3}$ Williams et al. reported ${ }^{4}$ that cleavage of Lrhamnose from ristocetin A removes this aggregating property. In a systematic study with aglyco-ristocetin ${ }^{5}(\mathbf{2})$ (Scheme 1 ) derivatives we found that deglycosylation of $\mathbf{1}$ retains the antibacterial activity, however $\mathbf{2}$ is not suitable for platelet aggregation tests due to its very low solubility in water. To improve solubility, we prepared derivatives of 2 containing $\beta$-D-glucopyranosyl and $\beta$-Dmaltosyl substituents attached through an $\mathrm{N}$-glycosylthiourea moiety. ${ }^{6}$ These derivatives possessed good antibacterial activity and did not induce platelet aggregation. These promising results prompted us to perform a systematic study on the influence of various sugar substituents on the biological activity of derivatives of 2 . In this work we here report on the synthesis and biological activity of several new sugar derivatives of $\mathbf{2}$. For conjugation of 1 we have chosen D-glucose, D-mannose and L-rhamnose, since

\footnotetext{
* Corresponding author. Tel.: +36 52512900 22895; fax: +36 52512914.

E-mail address: herczeghp@gmail.com (P. Herczegh).
}

the ristocetin molecule also contains these saccharides. Another glycopeptide antibiotic, teicoplanin has $\mathrm{N}$-acetyl-D-glucosamine substituent, consequently this sugar was also chosen for the derivatisation of $\mathbf{1}$. Following our diazo-transfer-click reaction sequence $^{7} \mathbf{3}$ was chosen as the starting compound. Copper-catalyzed 1,3-dipolar cycloaddition reaction ('click reaction') ${ }^{8}$ of the latter with per-O-acetylated propargyl glycosides ${ }^{9}$ resulted in the carbohydrate-substituted aglycons 4a-8a. Zemplén deacetylation ${ }^{10}$ of the sugar acetate moieties led to the glycosyl-oxymethyl-triazolyl derivatives of the ristocetin aglycon carrying saccharides with $\alpha-\mathrm{D}-$ glucopyranosyl (4b), $\alpha$-D-mannopyranosyl (5b), $\alpha$-D-maltopyranosyl (6b), $\alpha$-D- $N$-acetylglucosaminyl (7b) and $\alpha$-L-rhamnopyranosyl (8b) configuration (Scheme 2).

Evaluation of the biological properties of these derivatives (including the per- $O$-acetates) against Gram-positive bacteria demonstrated that introduction of the sugar moieties at the N-terminus into the ristocetin A aglycon molecule had a beneficial effect on the antibacterial activity. From an analysis of the data summarized in Table 1, it can be seen that the most of the new derivatives displayed higher activity than 1. The sugar derivatives 4-7 had good to excellent bacteriostatic activity against the test organisms, including glycopeptide-resistant enterococci. Interestingly, in this small group of compounds, the configuration of the sugar part (D-sugars) exhibited only a slight influence on the MIC values. 


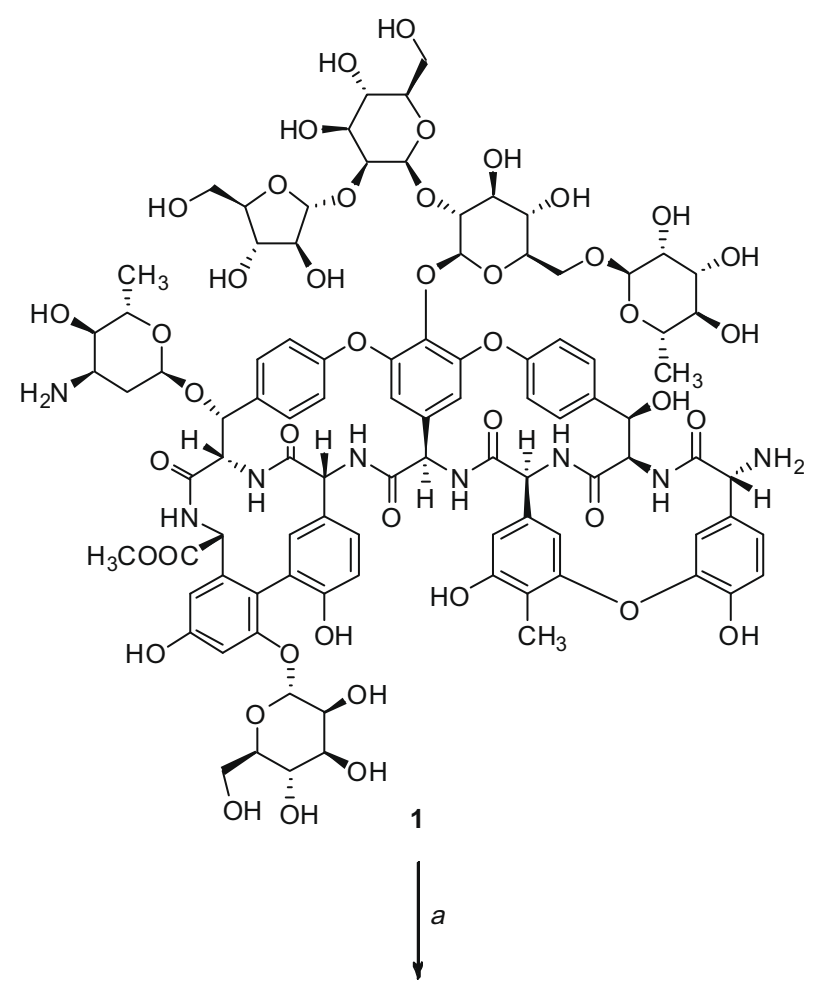

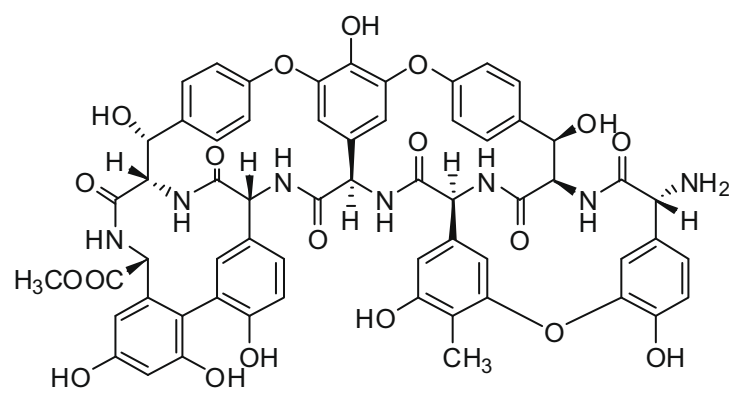

2

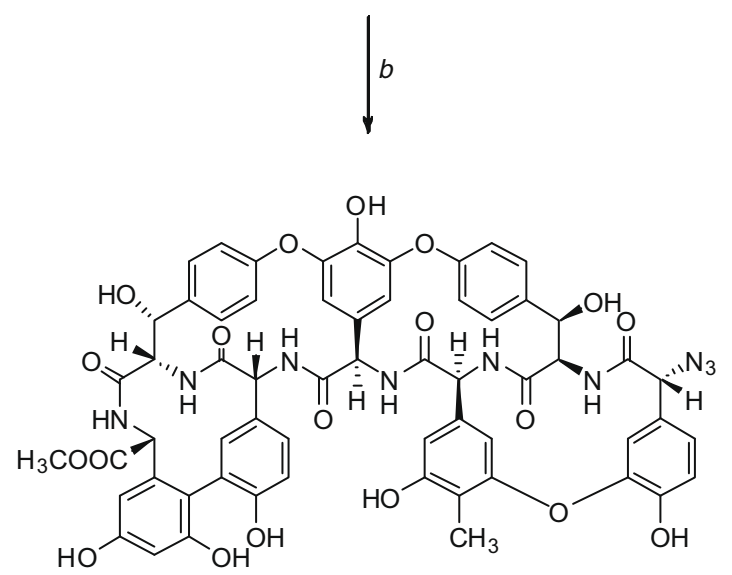

3

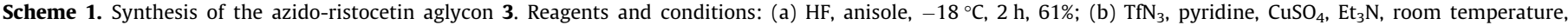
overnight, $58 \%$.

Derivatives 8a and $\mathbf{8 b}$ containing rhamnosyl glycosides of the L-sugar series possessed much lower activity indicating the role of the stereochemistry in the antibacterial activity. It has to be noted that there is only a slight difference between the MIC values of compounds having acetylated (a series) or free sugars (b series), which can be explained by a possible deacetylation in the culture media by aspecific esterases. The anti-influenza virus activity of the prepared substances was also evaluated, since we 


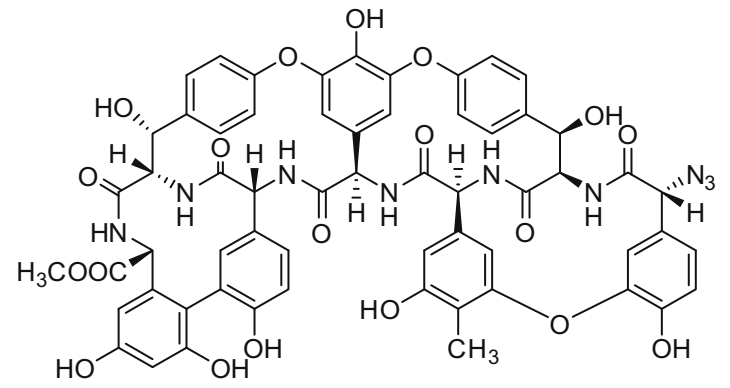

3<smiles>[3H][V]</smiles>

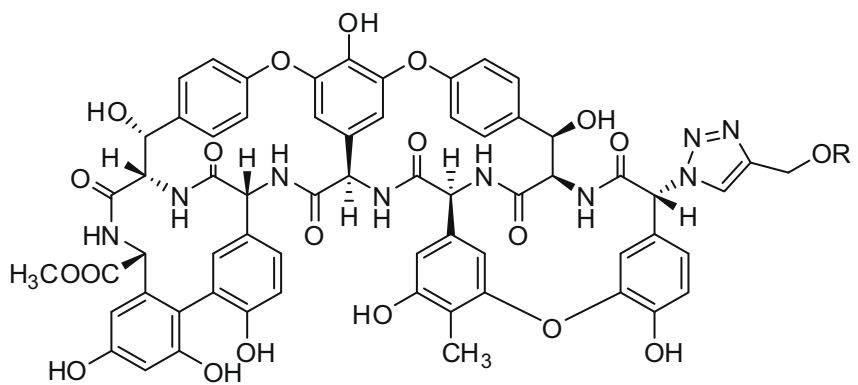
4a-8a

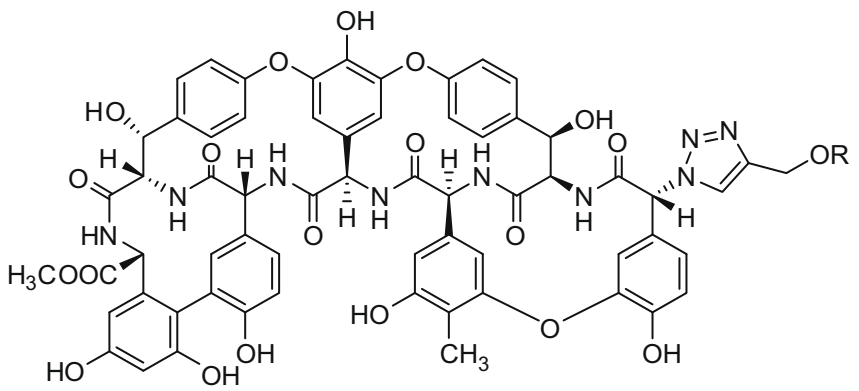

$4 b-8 b$
$\mathrm{R}=$

$4 a$<smiles>CC(=O)OCC1OC(C)C(OC(C)=O)C(C)C1OC(C)=O</smiles>

$5 a$<smiles>CC(=O)OCC1OC(C)C(OC(C)=O)C(C)C1OC(C)=O</smiles>

$6 a$

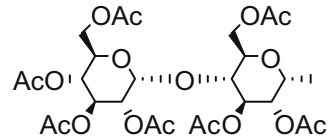

$7 a$

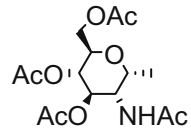

$8 a$

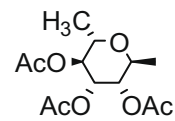

$\mathrm{R}=$

4b<smiles>C[C@H]1O[C@H](CO)[C@@H](O)[C@H](O)[C@H]1O</smiles>

$5 b$<smiles>C[C@@H]1O[C@H](CO)[C@@H](O)[C@H](O)[C@H]1O</smiles>

$6 b$<smiles>C[C@@H]1O[C@H](CO)[C@@H](O[C@@H]2O[C@H](CO)[C@@H](O)[C@H](O)[C@H]2O)[C@H](O)[C@H]1O</smiles>

$7 b$<smiles>CC(=O)N[C@H]1O[C@H](O)[C@@H](O)[C@H](O)[C@H]1O</smiles>

$8 b$

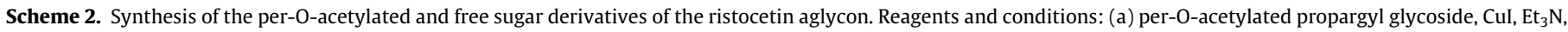
dry DMF, room temperature, overnight, 38-53\%; (b) NaOMe, $\mathrm{MeOH}$, room temperature, overnight, 87-96\%.

recently discovered good to excellent activities of some derivatives of $1 .{ }^{11}$ The cell-culture based assays to determine the inhibitory effect on influenza virus replication against, have been published elsewhere. ${ }^{11}$ Briefly, the antiviral activity was expressed as the $50 \%$ effective concentration $\left(\mathrm{EC}_{50}\right)$, or compound concentration producing $50 \%$ inhibition of influenza virus replication (as determined by microscopic or spectrophotometric assays). These experiments also allowed to estimate the cytotoxicity of the test compounds. As shown in Table 2, compounds 4a,b-7a,b exhibited antiviral activity against influenza virus, with the highest activity being noted for the A/H1N1 subtype (antiviral $\mathrm{EC}_{50}$ values in the range of $6-16 \mu \mathrm{M}$ ). These four compounds produced minimal, if any, cytotoxicity at 70-100 $\mu \mathrm{M}$. We have also studied the influence of the presence of sugar moieties on blood platelet aggregation properties. In about $0.1 \mathrm{mg} / \mathrm{mL}$ concentration the D-glucose and D-maltose analogs $\mathbf{4 b}$ and $\mathbf{6 b}$ inhibited the ristocetin induced platelet aggregation. The D-mannose and D-glucosamine derivatives $\mathbf{5 b}$ and $\mathbf{7 b}$ had no influence, but the L-rhamnose derivative $\mathbf{8 b}$ increased the intensity of aggregation. 
Table 1

Antibacterial activity of the new sugar derivatives of the ristocetin aglycon

\begin{tabular}{|c|c|c|c|c|c|c|c|c|c|c|c|c|}
\hline \multirow[t]{2}{*}{ Test microorganism } & \multicolumn{12}{|c|}{$\mathrm{MIC} / \mathrm{MBC}(\mu \mathrm{g} / \mathrm{mL})$} \\
\hline & Ristocetin & 3 & $4 a$ & $4 b$ & $5 a$ & $5 \mathbf{b}$ & $6 a$ & $\mathbf{6 b}$ & $7 \mathbf{a}$ & 7b & $8 \mathbf{a}$ & $\mathbf{8 b}$ \\
\hline $\begin{array}{l}\text { ATCC } 6633 \\
\text { B. subtilis }\end{array}$ & $2 / 4$ & $1 / 4$ & $8 / 16$ & $2 / 8$ & $4 / 8$ & $4 / 4$ & $8 / 8$ & $4 / 4$ & $2 / 8$ & $4 / 8$ & $32 / 32$ & $16 / 16$ \\
\hline ATCC 33591 MSSA & $16 / 64$ & $1 / 2$ & $4 / 8$ & $2 / 128$ & $2 / 4$ & $4 / 16$ & $1 / 4$ & $2 / 256$ & $1 / 64$ & $4 / 4$ & $16 / 32$ & $8 / 16$ \\
\hline ATCC 29213 MRSA & $16 / 64$ & $2 / 2$ & $4 / 8$ & $2 / 256$ & $2 / 4$ & $2 / 216$ & $1 / 4$ & $4 / 256$ & $0.5 / 256$ & $2 / 2$ & $16 / 32$ & $8 / 8$ \\
\hline $\begin{array}{l}\text { ATCC } 35984 \\
\text { S. epidermidis } \\
\text { Biofilm-positive }\end{array}$ & $32 / 64$ & $8 / 16$ & $2 / 4$ & $4 / 4$ & $4 / 8$ & $4 / 8$ & $4 / 8$ & $8 / 8$ & $2 / 2$ & $4 / 4$ & $16 / 16$ & $16 / 16$ \\
\hline S. epidermidis & $4 / 8$ & $16 / 16$ & $2 / 4$ & $4 / 16$ & $4 / 4$ & $4 / 8$ & $4 / 4$ & $4 / 8$ & $1 / 2$ & $2 / 4$ & $16 / 32$ & $16 / 16$ \\
\hline $\begin{array}{l}\text { ATCC } 29212 \\
\text { E. faecalis } \\
\text { Vanco: S } \\
\text { Teico: S }\end{array}$ & $4 / 256$ & $8 / 16$ & $8 / 256$ & $4 / 256$ & $4 / 128$ & $8 / 256$ & $4 / 256$ & $4 / 256$ & $4 / 256$ & $8 / 256$ & $32 / 256$ & $32 / 256$ \\
\hline $\begin{array}{c}\text { ATCC } 51299 \\
\text { E. faecalis } \\
\text { Vanco: R } \\
\text { Teico: S } \\
\text { VanB + }\end{array}$ & $128 / 256$ & $64 / 128$ & $16 / 256$ & $8 / 256$ & $8 / 256$ & $16 / 256$ & $8 / 256$ & $32 / 256$ & $4 / 256$ & $16 / 256$ & $128 / 256$ & $64 / 128$ \\
\hline $\begin{array}{l}15376^{\mathrm{a}} \\
\text { E. faecalis } \\
\text { Vanco: R } \\
\text { Teico: R } \\
\text { VanA + }\end{array}$ & $128 / 256$ & $>256$ & $8 / 256$ & $4 / 256$ & $2 / 128$ & $16 / 64$ & $2 / 256$ & $8 / 256$ & $2 / 256$ & $8 / 256$ & $16 / 256$ & $16 / 256$ \\
\hline
\end{tabular}

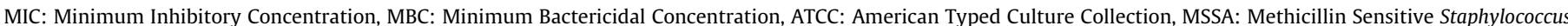

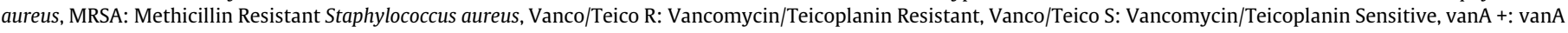
gene positive, vanB +: vanB gene positive.

${ }^{\text {a }}$ Ref. 12.

Table 2

Anti-influenza virus activity of the new sugar derivatives of the ristocetin aglycon

\begin{tabular}{|c|c|c|c|c|c|c|c|c|c|}
\hline \multirow[t]{3}{*}{ Compound } & \multirow[t]{3}{*}{ Concentration unit } & \multicolumn{2}{|r|}{ Cytotoxicity } & \multicolumn{6}{|c|}{ Antiviral $\mathrm{EC}_{50}{ }^{\mathrm{c}}$} \\
\hline & & \multirow[t]{2}{*}{$\mathrm{CC}_{50}^{\mathrm{a}}$} & \multirow[t]{2}{*}{ Minimum cytotoxic concentration ${ }^{\mathrm{b}}$} & \multicolumn{2}{|c|}{ Influenza A/H1N1 } & \multicolumn{2}{|c|}{ Influenza A/H3N2 } & \multicolumn{2}{|c|}{ Influenza B } \\
\hline & & & & CPE & MTS & $\mathrm{CPE}$ & MTS & CPE & MTS \\
\hline 3 & $\mu \mathrm{M}$ & $\geqslant 53$ & 100 & 9.5 & 8.8 & $\geqslant 20$ & $\geqslant 9$ & $>100$ & $>100$ \\
\hline $4 \mathbf{a}$ & $\mu \mathrm{M}$ & $\geqslant 87$ & $\geqslant 100$ & 9.5 & 8.2 & $>100$ & $>100$ & $>100$ & $>100$ \\
\hline 4b & $\mu \mathrm{M}$ & $>100$ & $\geqslant 100$ & 14 & 16 & $\geqslant 45$ & $\geqslant 30$ & 32 & 33 \\
\hline $5 \mathbf{a}$ & $\mu \mathrm{M}$ & $>100$ & 20 & 4.0 & 5.0 & $>100$ & $>100$ & $>100$ & $>100$ \\
\hline $5 \mathbf{b}$ & $\mu \mathrm{M}$ & $>100$ & $\geqslant 100$ & 10 & 22 & $\geqslant 45$ & $\geqslant 46$ & $\geqslant 45$ & $\geqslant 50$ \\
\hline $6 \mathbf{a}$ & $\mu \mathrm{M}$ & 60 & 20 & $>100$ & $>100$ & $>100$ & $>100$ & $>100$ & $>100$ \\
\hline 6b & $\mu \mathrm{M}$ & $>100$ & $\geqslant 100$ & 16 & 20 & $>100$ & $>100$ & 52 & 61 \\
\hline 7a & $\mu \mathrm{M}$ & $\geqslant 70$ & 100 & 8.0 & 5.8 & $>100$ & $>100$ & $>100$ & $>100$ \\
\hline 7b & $\mu \mathrm{M}$ & $>100$ & $\geqslant 100$ & 9.0 & 8.7 & $\geqslant 45$ & $\geqslant 72$ & 32 & 40 \\
\hline $8 \mathbf{a}$ & $\mu \mathrm{M}$ & $>100$ & $>100$ & $>100$ & $>100$ & $>100$ & $>100$ & $>100$ & $>100$ \\
\hline $8 \mathbf{b}$ & $\mu \mathrm{M}$ & $>100$ & $>100$ & $>100$ & $>100$ & $>100$ & $>100$ & $>100$ & $>100$ \\
\hline Oseltamivir carboxylate & $\mu \mathrm{M}$ & $>100$ & $>100$ & 12 & 11 & 32 & 38 & 23 & 27 \\
\hline Ribavirin & $\mu \mathrm{M}$ & $>100$ & $>100$ & 9.0 & 11 & 9.0 & 8.7 & 4.0 & 4.7 \\
\hline Amantadine & $\mu \mathrm{M}$ & $>500$ & $>500$ & 20 & 19 & 7.0 & 9.2 & $>500$ & $>500$ \\
\hline Rimantadine & $\mu \mathrm{M}$ & $>500$ & $>500$ & 224 & 283 & 4.0 & 5.6 & $>500$ & $>500$ \\
\hline
\end{tabular}

CPE: cytopathic effect.

MTS: methyltetrazolium salt.

Data shown are the mean of two independent tests.

a $50 \%$ cytotoxic concentration, as determined by measuring the cell viability with the colorimetric formazan-based MTS assay.

b Minimum compound concentration that causes a microscopically detectable alteration of normal cell morphology.

c $50 \%$ effective concentration, or concentration producing $50 \%$ inhibition of virus-induced cytopathic effect, as determined by visual scoring of the CPE, or by measuring the cell viability with the colorimetric formazan-based MTS assay.

In summary, it is demonstrated that resubstitution of aglycoristocetin with saccharides by the 'click reaction' dramatically improves the antibacterial activity against glycopeptide-resistant enterococci and leads to anti-influenza virus derivatives. It turned out that the platelet aggregation activity can be effectively modified by introduction of various saccharides into the ristocetin aglycon molecule.

In order to improve and extend the antibacterial and antiviral activity, derivatisation of aglyco-ristocetin with further mono- and oligosaccharides with D and L configuration, as well as deoxy and deoxyamino sugars and other side chains with hydrophilic character is under way in our laboratory.

\section{Acknowledgments}

This work was supported by the Hungarian Research Fund OTKA through Grants 79126, T-46186, OTKA-NKTH CK 77515, and NK 68578. L.N. acknowledges the technical assistance from 
Leentje Persoons and the financial support from the Flemish Fonds voor Wetenschappelijk Onderzoek (FWO No. 9.0188.07) and the International Consortium for Anti-Virals (ICAV).

\section{References and notes}

1. Grundy, W. E.; Sinclair, A. C.; Theriault, R. J.; Goldstein, A. W.; Rickler, C. J.; Warren, H. B.; Oliver, T. I.; Sylvester, J. C. Antibiot. Annu. 1956-1957, 687.

2. Neu, H. C. Science 1992, 257, 1064.

3. Gangarosa, E. J.; Johnson, T. R.; Ramos, H. S. Arch. Intern. Med. 1960, 105, 83.

4. Bardsley, B.; Williams, D. H.; Baglin, T. P. Blood Coagul. Fibrinolysis 1998, 9, 241

5. Wanner, J.; Tang, D.; McComas, C. C.; Crowley, B. M.; Jiang, W.; Moss, J.; Boger, D. L. Bioorg. Med. Chem. Lett. 2003, 13, 1169.
6. Sztaricskai, F.; Pintér, G.; Rőth, E.; Herczegh, P.; Kardos, S.; Rozgonyi, F.; Boda, Z. J. Antibiot. 2007, 60, 529.

7. Pintér, G.; Batta, G.; Kéki, S.; Mándi, A.; Komáromi, I.; Takács-Novák, K.; Sztaricskai, F.; Rőth, E.; Ostorházi, E.; Rozgonyi, F.; Naesens, L.; Herczegh, P. J. Med. Chem. 2009, 52, 6053.

8. Meldal, M.; Tornoe, C. W. Chem. Rev. 2008, 108, 2952; Brik, A.; Wu, C.-Y.; Wong, C.-H. Org. Biomol. Chem. 2006, 4, 1446.

9. Roy, B.; Mukhopadhyay, B. Tetrahedron Lett. 2007, 48, 3783.

10. Zemplén, G.; Gerecs, Á.; Hadácsi, I. Chem.Ber. 1936, 69, 1827.

11. Naesens, L.; Vanderlinden, E.; Rőth, E.; Jekő, J.; Andrei, G.; Snoeck, R.; Panneconque, C.; Illyés, E.; Batta, G.; Herczegh, P.; Sztaricskai, F. Antiviral Res. 2009, 82, 89.

12. Ghidán, Á; Jeney, Cs.; Maródi, L. Cs.; Csiszár, K.; Rozgonyi, F. J. Antimicrob. Chemother. 2000, 46, 325. 